risks useful for genetic counselling". It does all these things successfully. There are chapters on central nervous system malformations, phacomatoses and tumours, cerebral degenerative disorders of childhood (by E M Brett), extrapyramidal disorders, muscle disease, peripheral neuropathies, hereditary ataxias and paraplegias, disorders of DNA repair, multifactorial inheritance and neurological disease (including multiple sclerosis), and dementia and epilepsy.

Each disorder or group of disorders is covered by a brief clinical description, a critical analysis of the relevant genetic data, and information concerning recurrence risks. This is a very practical book, and the author attempts to answer the frequently asked questions about variation in severity in a number of diseases, for example, neurofibromatosis and the hereditary motor and sensory neuropathies. She does not attempt to include every rare neurogenetic disorder, but concentrates on common or important clinical problems. There is very little with which to quibble and there are no major omissions.

Clinical geneticists will find this volume extremely useful; paediatricians and neurologists at all levels will want to refer to it often enough to think about buying their own copy.

A E Harding

\section{Biofuture. Confronting the Genetic Era}

By Burke K Zimmerman. (Pp xi +305 ; figures + tables. \$16.95.) New York, London: Plenum Press. 1984.

This is a rather wordy account of the past, present, and possible future of biotechnology. Dr Zimmerman uses a personal and chatty style as he introduces his reader to the existing applications of molecular biology in all walks of life and then goes on to speculate on how developments in these various fields may be used for better or for worse in time to come. His thesis ranges from the selection of human characteristics such as intelligence and behaviour, to the awesome prospects of biological warfare and control of the ageing process.

There is much in this text to be commended. Fascinating snippets of gossip are interspersed with erudite expositions of scientific achievement and one imagines that Dr Zimmerman would be a most entertaining guest on a late night chat show. His treatise is stimulating, provocative, and, as was intended, disturbing. However, one suspects that much of the impact of this book will be diminished on two counts. Firstly, the author's facility with words is matched by his fondness for applying them to the extent that it is. sometimes difficult to follow his train of thought. Secondly, it is not clear for whom this book is intended since it is in parts too technical for the lay reader but too basic for the well informed.

In summary this is a thoughtful and balanced account of molecular genetics and its wider implications which will provide pleasant light reading for those involved in medical genetics. It would not, however, rank as a high priority purchase.

\section{D Young}

\section{Black Caribs. A Case Study in Biocultural Adaptation} Current Developments in Anthropological Genetics Volume 3. Edited by M H Crawford. (Pp xvii + 395; figures + tables. \$59.50.) New York, London: Plenum. 1984.

This volume presents the results of an intensive investigation of the Black Caribs of the coast of Honduras and St Vincent Island. The Black Caribs or Garifuna derive from a mixture of West African slaves with Arawak and Carib Indians on the island of St Vincent between 1517 and 1646, and most of the surviving population were transported to the mainland in 1797 where, as their numbers grew, they spread out to found settlements along the Caribbean coast.

The first part of this book is devoted to historical, social, cultural, and demographic details, and shows both the advantages and the disadvantages of this population for study. The linear distribution of small settlements along the coast provides what seems to be a model situation for examining unidimensional gene flow; its utilisation is inhibited by the cultural habits of the population, widespread travelling, the system of consanguineal households which provide stability in the absence of permanent males, and the difficulties of obtaining accurate demographic information. Part 2 deals with morphology. The data on growth show that there are real biological differences associated with the ethnic divisions that exist. The Garifuna children are consistently smaller and less well nourished than the sympatric Creole, with less efficient weaning, greater frequencies of chronic diarrhoea, and episodes of hospitalisation, leading to early differential mortality, not only within the population but also between the populations. There is an interesting contrast in the differentiation of the two populations by skin colour and anthropometry with the homogeneity shown by the dental and dermatoglyphic data. Blood pressure data are examined by an interesting combination of methods, 